\title{
La poliorcética. El éxito asegurado en las operaciones de asedio
}

\author{
Rubén SÁEz Abad
}

Doctor en historia

\begin{abstract}
RESUMEN ABSTRACT
En Roma, la guerra de asedio fue muy importante en las campañas militares. A través de este artículo, se estudian las máquinas de asedio usadas por las legiones y su influencia en las técnicas

In Roma, siege war was very important for military campaigns. Through this article, we study the siege machines used by legions and his influence in the techniques of roman combat.
\end{abstract} romanas de combate.

PALABRA CLAVE Artillería, maquinaria, asedio.
KEY WORDS

Artillery, machinery, siege.

\section{INTRODUCCIÓN}

Si partimos de la premisa de que, prácticamente, el 90\% de los asedios llevados a cabo por el ejército romano terminaron con éxito, a través de este artículo se van a analizar cuáles eran las técnicas y máquinas empleadas por las legiones y que eran capaces de garantizar esa alta efectividad.

Desde el siglo Ix a. C., el ataque a las defensas urbanas se convirtió en una práctica militar muy habitual dentro del territorio de Oriente Próximo. Este hecho se produjo debido a la proliferación en el número de ciudades y a su importancia estratégica creciente, como organizadoras y vertebradoras del espacio territorial. Cualquier imperio que quisiera extender sus dominios más allá de su territorio estaba obligado a atacar los muros de las ciudades vecinas. No se podía ocupar el 
espacio rural, dejando a su espalda los grandes núcleos sin conquistar, desde los que poder ser sorprendido. Fue esta necesidad de tomar las grandes ciudades, la que condujo al surgimiento de la poliorcética como ciencia.

En Roma, la guerra de asedio ocupó un papel fundamental en la estrategia de las campañas militares. Los asedios resultaban mucho más numerosos que las batallas en campo abierto, comprendiendo dentro de este grupo de operaciones, desde los enfrentamientos a pequeña escala frente a terraplenes fortalecidos con empalizadas hasta los asaltos a las grandes plazas fortificadas.

A menudo, era muy pocos los jefes militares que se inclinaban por las batallas campales para resolver un conflicto, ya que podía suponer la pérdida de un gran número de soldados, que luego resultaban claves para el desarrollo de las campañas de larga duración. Y, en muy pocas ocasiones, estos enfrentamientos en campo abierto resultaban definitivos, siendo obligado el vencedor a conquistar las principales plazas fortificadas para ganar la guerra. De ahí que, los comandantes al mando, fueran muy reacios a arriesgar un elevado número de soldados en un solo choque.

Este hecho llevó a que las ciudades se convirtieron, por tanto, en el principal elemento a tomar en los enfrentamientos armados. Si un invasor se decidía a lanzar una campaña evitando los recintos amurallados, corría el riesgo de ser hostigado por los defensores y de que fueran cortadas sus líneas de abastecimiento, algo que resultaba clave para el desarrollo de cualquier operación militar a gran escala en territorio enemigo. Al carácter notable de las fortalezas contribuía su excelente ubicación, normalmente en lugares estratégicos, de tal forma que controlaban los ríos y las vías de comunicación, tan necesarios para los movimientos en tierra hostil.

Era, precisamente, esta articulación del territorio y del espacio rural circundante la que conducía a que, cuando un ejército enemigo penetraba en el territorio controlado por una ciudad, la población rural buscara refugio en el interior de los recintos amurallados. En su huida abandonaban sus posesiones, llevándose todos sus objetos de valor, así como la comida de que disponían y sus armas.

A pesar de sus aportaciones a la defensa, en muchas ocasiones, cuando se presumía que el asedio iba a ser largo, se impedía la entrada de los campesinos al interior de la ciudad. Para una defensa activa bastaba con un reducido número de soldados, por lo que el aspecto que más se tenía en cuenta era el abastecimiento de víveres y, cuantas menos bocas hubiera que alimentar, más tiempo se podía resistir. Incluso en situaciones de carestía extrema cuando el asedio se intensificaba se expulsaban fuera de las murallas a las mujeres, niños y ancianos. Sólo permanecía dentro de la ciudad la masa de combatientes.

$\mathrm{Y}$, en el caso de que la ciudad se hubiera reforzado con víveres y tropas de refresco, previamente a la llegada de los enemigos ante los muros, el asedio llegaba a convertirse en una labor imposible. De ahí que, siempre que fuera posible, se in- 
tentaran tomar las fortalezas por medios diplomáticos, evitando un gasto de dinero innecesario.

En algunas ocasiones, la reputación de los jefes militares era tal que, con solo su aparición ante las murallas de la ciudad enemiga, se podía lograr que una plaza fortificada se rindiese o aceptase pactar, sin la necesidad de recurrir a asedios de larga duración. En el caso de que la diplomacia no lograra persuadir al enemigo para que rindiese la plaza, era necesario hacer un alarde de fuerza y aparecer ante las murallas con todo el equipo militar, tratando de convencer al enemigo de la imposibilidad de resistir. La rendición de una ciudad sin combatir sólo se producía cuando se presumía que el número de defensores iba a resultar insuficiente para poder resistir un asedio de entidad.

Pero, si la negociación fracasaba, algo que solía suceder en la mayor parte de las ocasiones, los asaltantes atacaban por medio de un asalto rápido para sondear la moral de las tropas del interior.

En cuanto a la tipología de los asedios, se podía tomar una ciudad de tres formas:

Repentina oppugnatio: es lo que actualmente conocemos como asalto. Esta práctica se realizaba contra ciudades mal defendidas pero con abundancia de víveres. La conquista por sorpresa de una ciudad se podía producir aprovechando alguna circunstancia propicia, como el mal tiempo que podía dificultar la visión, una luna adecuada que ocultara los movimientos de los atacantes o alguna estratagema basada en los engaños. Estas operaciones de asalto solían ser realizadas por grupos de tropas especializadas, que empleaban medios técnicos muy reducidos, como escalas de cuerda o soga, garfios y piquetas con las que se facilitaba la escalada de los muros. Este tipo de ataque producía un elevado número de bajas entre los atacantes, a no ser que el número de defensores fuera muy reducido. Un buen ejemplo de este tipo de técnica fue el asedio de Cartago Nova por Escipión el 209 a. C.

Obsidio u obsessio: consistía en bloquear la ciudad enemiga, evitando la llegada de víveres y tropas de socorro. Esta técnica podía ser de dos tipos: parcial o total, en función del grado alcanzado. El modelo parcial se basaba en la construcción de campos fortificados en posiciones de valor estratégico, normalmente enfrente de las puertas principales. En estos campos se almacenaban los víveres y el armamento y se daba refugio a los tránsfugas de la ciudad. De esta forma, las comunicaciones con el exterior eran notablemente perjudicadas, aunque no se interrumpían totalmente. Cuando el muro de asedio estaba encaminado a aislar por completo la ciudad del exterior, el bloqueo tomaba la forma de total. En este momento, las comunicaciones con el exterior se interrumpían en su totalidad, impidiendo la salida y entrada al recinto urbano. Para ello se construía una línea de bloqueo formada por castra, castella y una empalizada reforzada por torres. Este tipo de ataque se ponía en práctica contra ciudades que disponían de fortificaciones de 
entidad y escasos víveres con los que mantener a los defensores. La perfección e impermeabilidad del cerco resultaba fundamental de cara a las aspiraciones de los sitiadores. Quizás, los ejemplos más significativos del empleo de este tipo de técnica sean la circunvalación de Numancia por parte de Escipión el año 133 a. C. y la de Alesia por César el 52 a. C.

Longinqua oppugnatio: es el típico caso de asedio de larga duración y combina elementos de los dos anteriores. Así, tras aislar la ciudad de forma parcial o total, se ponía en marcha la maquinaria de asedio. Su uso solía reducirse a ciudades dotadas de buenas construcciones defensivas y de abundantes provisiones. El ejemplo más significativo de este tipo de asedio es el de Jerusalén por Tito el $70 \mathrm{~d}$. C.

Resumiendo, las estrategias para hacer caer una ciudad eran básicamente dos: rendirla por hambre o asaltarla y capturarla por la fuerza. La primera de las dos era la que suponía un menor coste humano. Lo único que tenía que hacer el atacante era protegerse de las salidas de los sitiados y de las operaciones de auxilio desde el exterior, evitando en todo momento que pudieran entrar dentro de la ciudad tropas de refresco y víveres. Pero, esta estrategia de ataque era muy lenta y resultaba excesivamente costosa, ya que obligaba a inmovilizar ante los muros enemigos un ejército durante espacios de tiempo prolongados, que podían llegar a ser incluso de varios años.

Para llevar a cabo las obras de asedio, el atacante debía disponer de un ejército de grandes dimensiones, que le permitiera controlar el campo que rodeaba la ciudad. Además, sus tropas debían estar preparadas para rechazar la posible llegada de contingentes de auxilio desde el territorio circundante y llevar a cabo, al mismo tiempo, el asalto de las defensas. Y, el mantenimiento de estas tropas requería grandes cantidades de dinero y alimentos, que podían obligar a levantar un asedio si se prolongaba demasiado.

De ahí que, se intentara por todos los medios reducir la duración de los asedios. Ahí es donde entraban en juego las máquinas, que contribuían a reducir el tiempo de las operaciones, y con él su coste. Una vez que había comenzado el ataque a una fortaleza, resultaba un deshonor retirarse y abandonarlo sin antes haber tomado la ciudad, lo que obligaba a los atacantes a redoblar sus esfuerzos.

La principal dificultad para conquistar una ciudad fortificada por la fuerza era superar las murallas. En este caso se podían:

- Superar las murallas por debajo para penetrar en la fortaleza por medio del minado.

- Superar las murallas por encima con escalas, sambucae (fig. 1) o torres de asedio (fig. 2).

- Atravesar las murallas, rompiendo un lienzo con el bombardeo de las piezas de artillería (fig. 4) o el golpeo de los arietes (fig. 3) y taladros. 


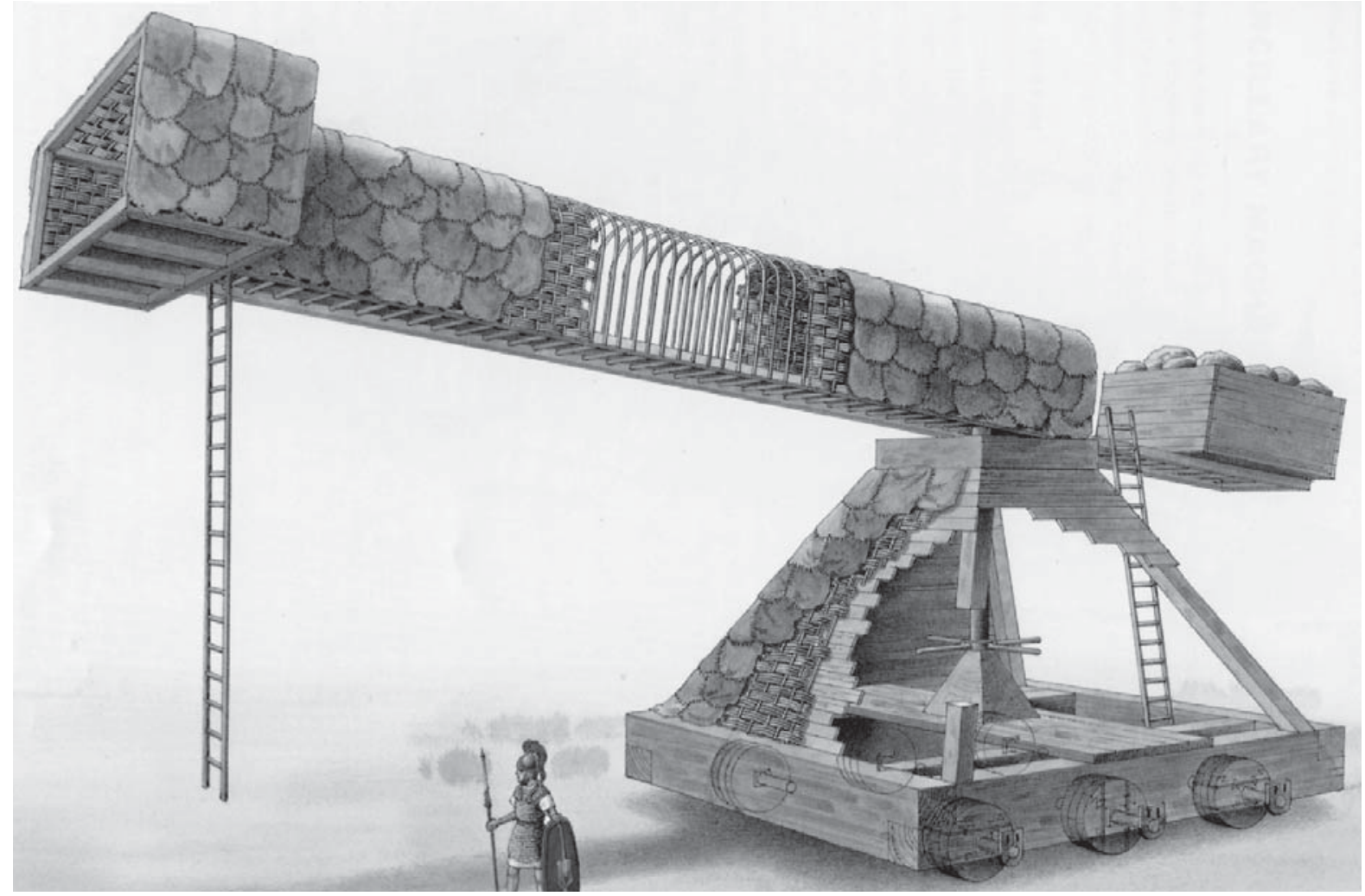

Fig. 1. Sambuca (Campbell, 2003).

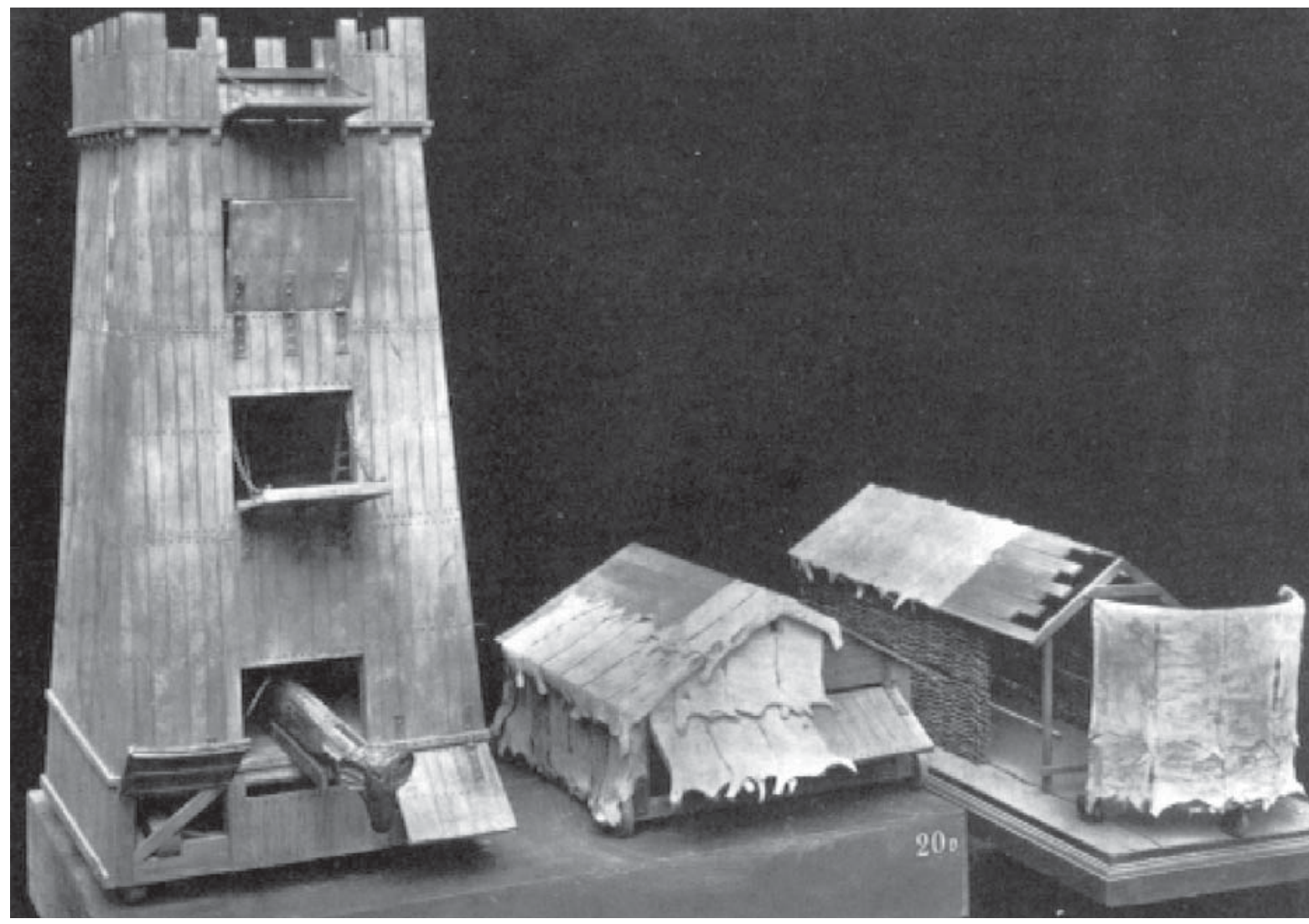

Fig. 2. Reconstrucción de una torre de asedio, un músculo, un pluteo y una vinea (Liberati, 1990). 


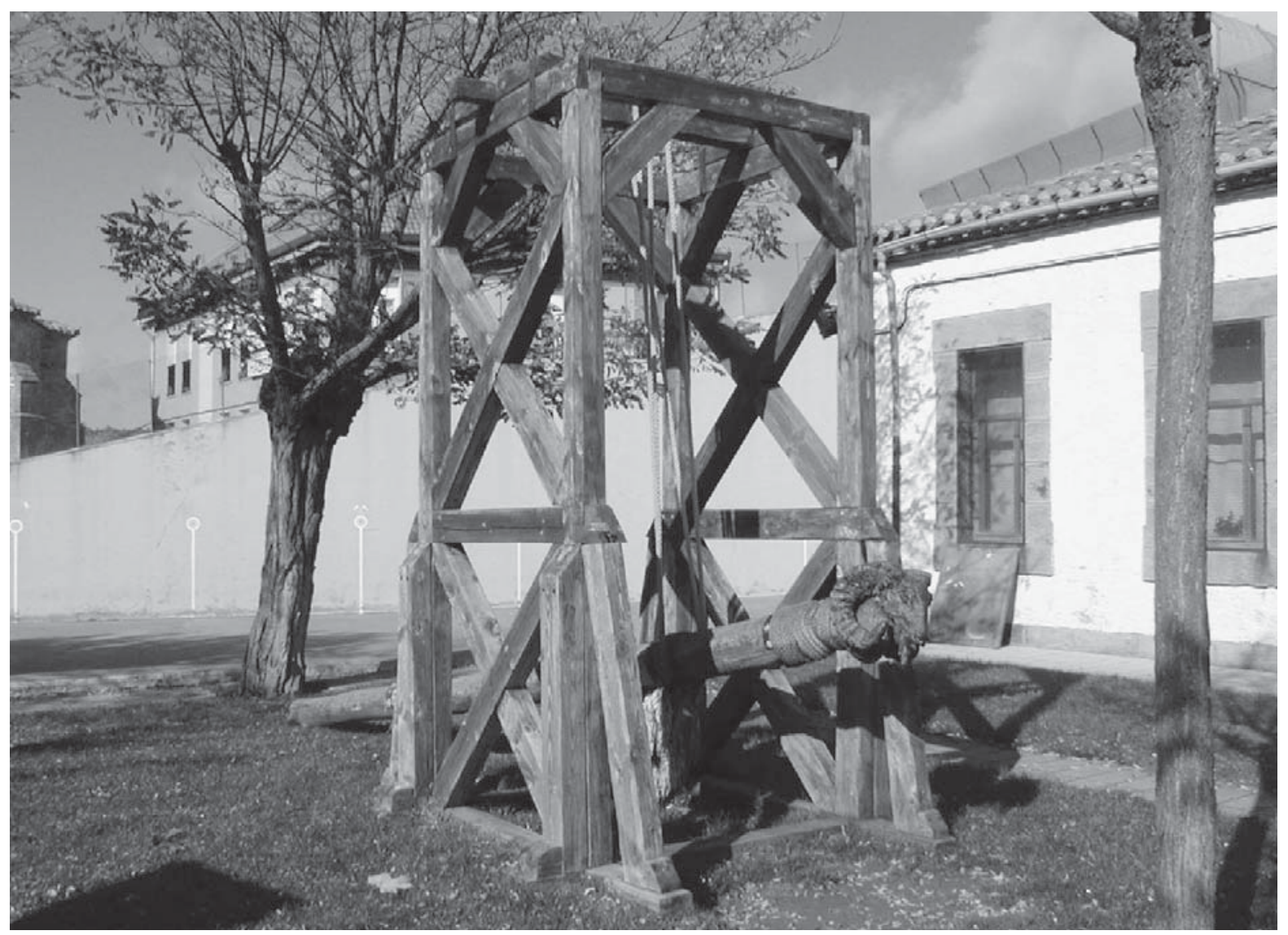

Fig. 3. Reconstrucción de un aries prensilis en Garray (Soria).

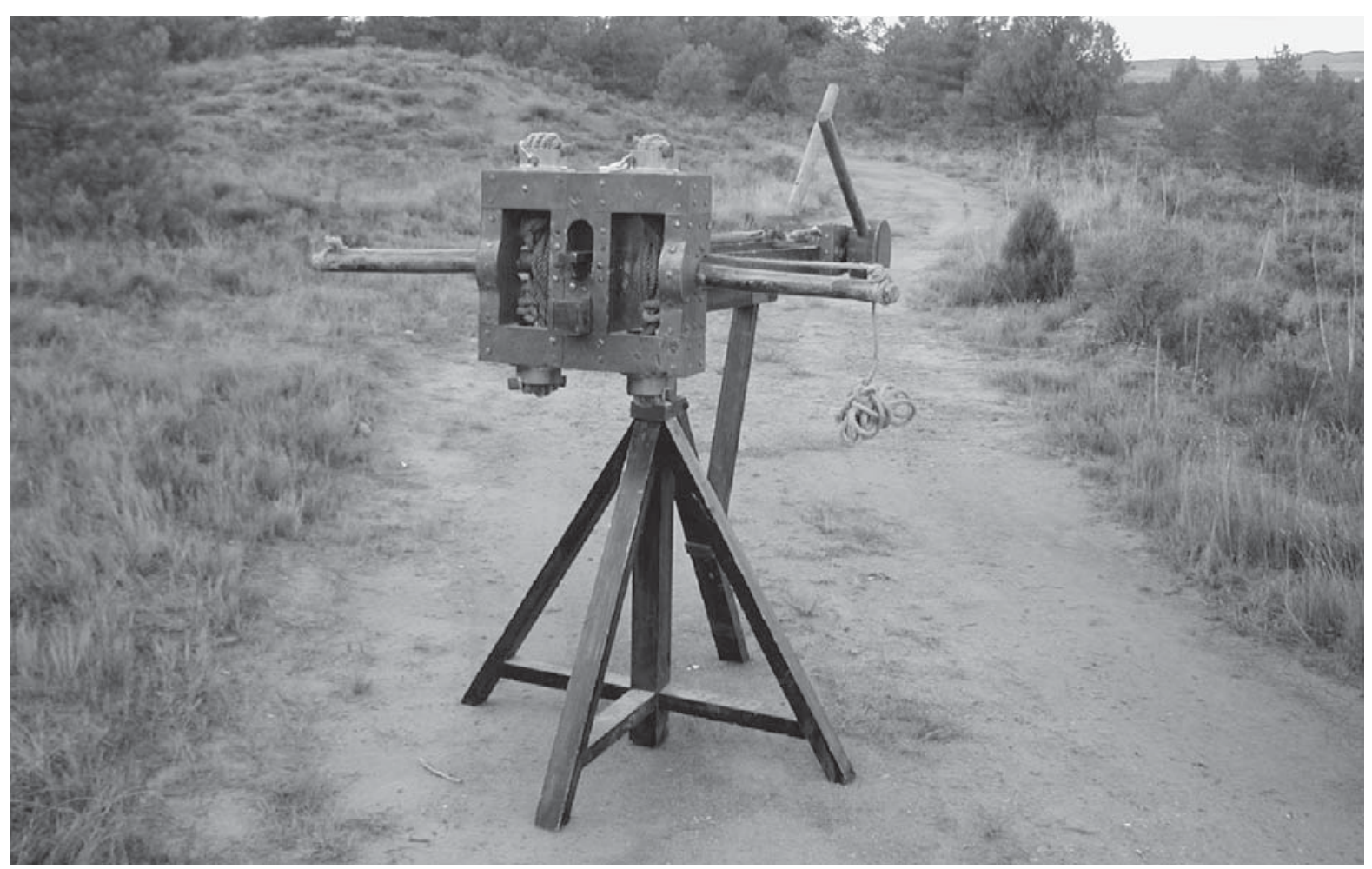

Fig. 4. Reconstrucción de la catapulta tipo scorpio de Rubén Sáez. 


\section{TÉCNICAS Y MÁQUINAS PARA LA SUPERACIÓN DE LAS MURALLAS}

\subsection{Superación de las murallas por su parte inferior: el minado}

Respecto a la superación de las murallas por su parte inferior, el trabajo de minado resultaba de gran interés en las operaciones poliorcéticas, pues no requería demasiado trabajo y su coste en pérdidas humanas era muy limitado. Las tareas de excavación podían tener dos objetivos diferentes: por un lado podían servir para conseguir penetrar en el interior de la plaza con un túnel o bien hacer que se cayera un tramo de las murallas y facilitar la entrada de los soldados a pie firme por la superficie, que era la técnica más habitual.

La forma de llevar a cabo las obras de minado consistía en atacar la base de los muros con la ayuda de picos. Para evitar que los soldados que llevaban a cabo estas operaciones fueran heridos se podían proteger con cobertizos móviles o trincheras cubiertas con tablones. Una vez que el túnel había superado los muros, el agujero excavado se apuntalaba con maderas, al igual que aún se hace hoy en día en los trabajos de minería subterránea, y se llenaba de materiales combustibles. De este modo, cuando se le prendía fuego al entibado, el túnel se derrumbaba, lo que arrastraba el sector amurallado que había quedado colgado. Para tratar de evitar los problemas derivados del minado, siempre que era posible las murallas se asentaban sobre rocas sólidas y se protegían en su parte frontal con fosos llenos de agua.

De cara a que las minas resultaran totalmente efectivas tenían que comenzar a excavarse a bastante distancia de las murallas. Resultaba conveniente que se ocultaran a la vista de los sitiados tras la protección de vallas, con la finalidad de asegurarse de que en el interior no se percataran que se estaba realizando ningún tipo de obra. Una vez que los defensores conocían de la existencia de las obras de minado, el problema residía en saber en qué lugar se estaban llevando a cabo, para tratar de contrarrestarlas.

La forma de conocer el punto exacto en el que se estaba llevando a cabo la excavación era con la colocación de escudos en el suelo. A causa de su especial construcción captaban hasta la menor vibración de la tierra que había debajo del sitio en el que se habían colocado. También resultaba útil el empleo de recipientes con agua, muy sensibles a cualquier movimiento.

La única forma de contrarrestar las minas era con el contraminado. Después de saber hacia qué lugar se dirigían las obras de minado, los sitiados construían desde el interior túneles que se cruzaran con los del enemigo. Tras encontrarse los dos grupos bajo tierra, se producía el enfrentamiento, que podía llegar a tomar el carácter de una verdadera batalla, en la que incluso podían ser empleadas piezas de artillería ligera. Del desenlace de este combate dependía que unos u otros alcanzaran sus objetivos. El fuego resultaba clave en este tipo de combate, ya que con los gases asfixiantes del humo era mucho más fácil lograr la victoria y expulsar al enemigo de las obras. 


\subsection{Superación de las murallas por su parte superior}

\subsubsection{Máquinas protectoras previas al acercamiento de las máquinas mayores}

Antes del acercamiento de las grandes máquinas a los muros, como las torres de asedio o los arietes, era necesario cegar los fosos que se encontraban delante de ellos y allanar el terreno de acceso a las defensas. Para esta función se empleaban diferentes máquinas, entre las que destacaban el mantelete, el portico, la vinea, el pluteo, el musculo o la tortuga.

El mantelete fue la primera forma de protección adoptada por los ejércitos para acercarse a los muros enemigos. En cuanto a su diseño, era una especie de muro frontal formado por un panel de grandes dimensiones. Los más simples estaban fabricados con mimbre y se utilizaban contra fortificaciones que no dispusieran de piezas de artillería. En cambio, si los enemigos disponían de catapultae o ballistae había que hacerlos más resistentes, de modo que pudieran resistir los impactos.

Con el fin de evitar los golpes de las piedras lanzadas desde el muro también podían estar acolchados o cubrir su frente con tierra, formando una especie de empalizada que, cuando fuera necesario, podía hacerse móvil y ser trasladada a otro lugar. En cualquier caso, siempre se protegían con pieles que evitaran que el fuego prendiera y era posible que se les dotara de ruedas para facilitar su movimiento.

El número de soldados necesarios para desplazar esta máquina variaría en función de su tamaño, pero normalmente era de al menos dos, mientras que el resto se situaba detrás al amparo de ella. Los ejemplares de menores dimensiones, como mínimo podían proteger de los disparos frontales un número de entre seis y ocho soldados, aunque los mayores podrían dar cabida a entre cuarenta y cincuenta.

El principal inconveniente de los manteletes residía en que por los lados laterales y por su parte superior resultaban vulnerables, lo que obligaría a que para resultar efectivos tuvieran que ser desplazados unos junto a otros, formando una especie de muro de grandes dimensiones.

Otra de las máquinas para proteger a los soldados era el pluteo (fig. 2). En cuanto a su constitución, tenía forma absidial y se desplazaba con la ayuda de tres ruedas dispuestas en los laterales y en la parte frontal. Era muy semejante al mantelete, aunque había transformado su forma y se había dotado de movilidad. Aumentaba algo la protección por los laterales respecto al predecesor, aunque seguía resultando vulnerable por su parte superior. El número de soldados que podía proteger variaba en función del tamaño, pero oscilaría entre los seis y los veinte.

Cuando los refugios estaban fijos recibían el nombre de porticos o vineae (fig. 2), en razón de su alargamiento. Constituían una especie de galería cubierta 
muy amplia, que unía la posición del sitiador con los muros de la fortaleza, como si de un túnel en superficie se tratara. La primera referencia a la construcción de estas estructuras porticadas de grandes dimensiones las encontramos en las operaciones de Julio César en la Galia, autor que se refiere a ellas como vineae aggere o vineae proferre.

Respecto a su diseño, la morfología de la vinea era con forma de cobertizo a dos aguas, de un tamaño más o menos estándar, situado en torno a los 5 metros de largo, 2,4 metros de ancho y 2,1 de alto. Para aumentar su protección estaba reforzada con tablas en el tejado y con mimbre entretejido en sus laterales. A pesar de que era una máquina estática, se le podía dar movilidad colocándole unas ruedas o rodillos, o simplemente se podía desplazar levantándola con la fuerza manual. La vinea, a causa de su mayor tamaño, era capaz de albergar más de veinte hombres armados y los protegía de una forma más segura que los manteletes.

Entre el grupo de máquinas protectores también se encontraba el músculo (fig. 2). La principal función de esta máquina era la de transportar en su interior a los obreros que tenían que llevar a cabo las labores de minado o el rellenado de los fosos. El nombre de musculo hace referencia a un pez pequeño que guiaba a las ballenas. Al igual que sucedía con este animal, estas máquinas actuaban de forma previa a los ingenios mayores, como eran las grandes torres de asedio.

Tenían forma de galería móvil con cubierta a dos aguas, construida con tablazón de madera y disponía de cuatro ruedas. Para facilitar las operaciones de los obreros contaba con paneles portátiles en los lados y en el frente, que podían ser levantados o bajados a placer, según por qué lado se decidiera extraer la tierra de las obras.

Pero, el principal elemento protector que permitía el acercamiento de los soldados para llevar a cabo las tareas de asedio era la tortuga. Se le dio este nombre por su semejanza con este animal, pues del mismo modo sacaba y escondía la cabeza del ariete que portaba para golpear los muros.

Respecto a su diseño, era semejante a las anteriores, con cubierta a dos aguas, reforzada por tablones en su tejado y en sus laterales. Encima de esta tablazón se ponían refuerzos espesos de varas menudas, para terminar tapando todo con una doble capa de pieles sin curtir rellenas de algas, de paja macerada con vinagre o de barro. De esta forma, era capaz de resistir los impactos de las ballistae y tampoco ardía al impactar sobre ella los proyectiles incendiarios.

Cuando las tortugas tenían como finalidad proteger equipos de zapadores, el frente tenía que ser en forma de triángulo, para poder acercarse mejor a las murallas y evitar que los proyectiles las golpearan directamente y resbalaran por su inclinación. Pero, la tortuga no sólo era un elemento pasivo, sino que también solía ir armada con una hoz, cuya misión era mover los sillares de las murallas. Al igual que sucedía con las torres de asedio, también podía portar un ariete con el que batir los muros, siendo conocida en este último caso como testudo arietata. 
Los autores no coinciden en cual sería el diseño de esta máquina, que podría ir desde estas concepciones más clásicas descritas con anterioridad hasta otras muy novedosas como la aportada por Campbell (Campbell, 2003b), que presenta un diseño semejante a una pirámide con un sistema de cuatro ruedas en su interior. Sin embargo, este último modelo plantea ciertos problemas, sobre todo de disponibilidad de espacio en su interior, aunque facilita la evacuación de los proyectiles que la golpean, sobre todo gracias a su recubrimiento con pieles rellenas de algas.

La testudo arietata descrita por Apolodoro era muy diferente a la empleada varios siglos antes. Se componía de un chasis, sobre el que se instalaba una estructura semejante a un triángulo, en cuyo interior se disponía el ariete. Gracias a su especial diseño actuaba como deflector de los proyectiles de las piezas de artillería.

El último modelo de tortuga conocido aparece descrito en la obra de Apolodoro y tenía forma de proa de barco, con dos planchas de madera verticales que formaban un ángulo de $45^{\circ}$. Disponía de una pata de apoyo y de tres ruedas, una en la parte delantera y otras dos en la trasera. Se reforzaba con placas de hierro en su parte frontal. La principal función de esta máquina era proteger los soldados cuando realizaban operaciones de acercamiento en lugares escarpados, evitando que troncos, toneles o piedras redondas pudieran arrollar a las tropas de infantería.

\subsubsection{Máquinas para la superación de las murallas por altura}

Una vez que los soldados ya habían allanado los fosos y se había preparado el terreno para el desplazamiento de las máquinas mayores, éstas entraban en acción.

El método más barato y rápido para tratar de tomar una fortaleza era la superación de los muros con la ayuda de escalas, pero también era el más peligroso y el que solía costar un mayor número de bajas entre los ejércitos atacantes. Las escalas podían tomar diseños muy diferentes, desde modelos simples y que no serían más que escaleras de madera, hasta otros muy complejos dotados de mecanismos elevatorios.

A menudo, por muy simples que fueran, disponían de ganchos de hierro en su parte superior, que permitían su anclaje en las almenas y de refuerzos en la base, de forma que se fijaran con seguridad en el suelo. Si era necesario, cuando las escalas se apoyaban en las murallas, también podían emplear diferentes tipos de calzos, que facilitaran que no se perdiera pie, principal problema de los modelos más simples. Toda precaución era poca para facilitar que resultaran efectivas y se perdiera el menor número de vidas posible. Cuando el ataque era nocturno y sigiloso, las escaleras de madera eran sustituidas por otras portátiles construidas con tiras de cuero o cuerda, muy semejantes a las actuales empleadas en escalada. 
Resultaba muy importante que, tanto los modelos simples de escalas como los complejos, se hubieran probado antes de realizar el ataque. Estas pruebas permitían asegurar su resistencia de forma previa. De este modo, se evitaba que se vinieran abajo por el exceso de peso producido por el gran número de soldados que subían por ellas al mismo tiempo.

La sambuca (fig. 1) era otro de los ingenios que facilitaban la elevación de los soldados hasta el interior de las defensas. A pesar de que sus principales aplicaciones se encontraban en los asedios navales, también se empleó para la guerra terrestre.

El ingenio consistía básicamente en una escalera de una altura igual a la muralla que se pretendía asaltar. Tenía barandillas a los lados y estaba protegida en toda su extensión por medio de pieles, para evitar que los asaltantes quedaran al descubierto en el momento de la ascensión. En la parte superior disponía de una especie de plataforma sobre la que se ubicaban arqueros. Con el objetivo de contrarrestar el peso de los soldados que había en un extremo, en el opuesto se colocaba una caja con plomo, que variaba de peso en función de las necesidades.

Los soldados accedían al interior por delante utilizando una escalera adosada al cuerpo principal. Cuando todos estaban dentro, se colocaba el plomo en el contrapeso hasta equilibrarlo. En ese momento, la sambuca pasaba de una posición totalmente horizontal hasta la que tendría definitivamente frente a las murallas.

Tras haber probado la máquina, los soldados descendían hasta el suelo y se acercaba el ingenio hasta la orilla de los muros. Tratando de evitar que fuera destruida, lo más conveniente era que fuera apoyada por torres de asedio dotadas de piezas de artillería en sus flancos. Así, se lograban neutralizar los proyectiles arrojados desde la muralla.

Cuando ya se había alcanzado el pie de los muros y estaba fuera del alcance de la artillería, los soldados subían de nuevo a la máquina que ya tenía los contrapesos calibrados. Se acercaba, entonces, hasta apoyarse en las murallas y se abría la trampilla a través de la que ascendían las tropas. Siguiendo a los primeros soldados que establecían una cabeza de puente, un reguero continuo se lanzaba a través de este pasillo cubierto hacia las defensas.

Sin embargo, a pesar de todos estos ingenios, las mayores máquinas de asedio empleadas para superar las murallas por su parte superior eran las torres de asedio (fig. 2). Estos ingenios podían alcanzar dimensiones descomunales, que variaban en función de la altura de los muros que debieran superar, aunque no tenían ningún problema para pasar de 20 metros de alto. Al mismo tiempo, constituían las máquinas pesadas más complejas por el variado equipamiento que desplazaban. Lo más normal en las máquinas de mayores dimensiones era la presencia de arietes, puentes de desembarco y piezas de artillería, en sus variantes para lanzar flechas y piedras. 
Los arietes basculantes se encontraban en el piso inferior y eran manejados por docenas de hombres resguardados en su interior, que batían sin descanso la parte más baja del recinto amurallado. En las alturas siguientes había ballistae de grandes dimensiones, cuya finalidad era la de bombardear sin descanso los muros. A la altura de la muralla se situaban puentes de desembarco. Por encima de ellos, en posición dominante, había baterías de catapultas, que disparaban flechas y que servían para limpiar las almenas. En este piso también se podían disponer ballistae de pequeño calibres que funcionaran como arma antipersonal y para arrojar proyectiles incendiarios impregnados de pez, aceite y petróleo. Todas estas baterías, junto a los arqueros, honderos y lanzadores de jabalina que se alternaban con ellas, proporcionaban un fuego de cobertura adecuado para la ocupación de la muralla por parte de los soldados que cruzaban por las pasarelas.

La torre de asedio se convertía, por tanto, en una máquina perfecta, ya que combinaba tanto el ataque desde cerca como a distancia, otorgando una enorme versatilidad al atacante. A pesar de todo, las torres de asedio multiplicaban su efectividad cuando lograban acercarse a la muralla y podían desplegar sus puentes de desembarco.

El tamaño de los pisos variaba, siendo los más bajos de mayores dimensiones, de modo que albergaran las máquinas mayores. Para acceder a cada uno de ellos, en la parte trasera de la torre había dos escaleras, una de subida y otra de bajada. De esta forma, se favorecía la libre circulación de tropas y el buen funcionamiento en los asedios, sin que se estorbaran los relevos de los soldados.

Estas inmensas máquinas de guerra se hacían avanzar mediante la fuerza muscular de sus ocupantes o con la ayuda de grandes norias, cabrestantes o polipastos. También se podían emplear sistemas de poleas inversas, de modo que, tirando en dirección contraria a los muros, la máquina avanzaba hacia ellos. Así, los sitiadores podían acercarse sin peligro a las fortalezas enemigas y penetrar en ellas superando sus murallas.

El funcionamiento de estas máquinas era el siguiente: las torres se hacían avanzar hacia las murallas y, una vez que estaban lo suficientemente cerca, arrojaban desde ellas los puentes de desembarco encima de la muralla. Los soldados de la torre avanzaban por la pasarela y entablaban una lucha cuerpo a cuerpo con los defensores para hacerse con el control de un sector de los muros. Si el primer grupo de atacantes lograba establecer una cabeza de puente, una corriente continua de soldados accedía desde la torre hasta ocupar las defensas de la ciudad.

Desde el punto de vista atacante, el principal inconveniente de esta máquina, a la hora de lanzar un ataque era que su puesta en funcionamiento nunca pillaba por sorpresa a los defensores, que la veían aproximarse a larga distancia. A esto se unía que, previamente a la maniobra de aproximación de la torre, el suelo por el que se iba a aproximar a los muros debía ser allanado. En el caso de la presencia 
de fosos, era necesario que éstos fueran cegados. De una o de otra forma, el ejército atacante se veía obligado a construir una especie de calzada en el suelo con tierra fuertemente comprimida y un entramado de troncos para darle estabilidad. En algunos casos, como en el asedio de Azaila, la rampa estaba construida en opus caementicium. Todo este espacio de tiempo dedicado a las labores previas a la aproximación de las torres de asedio, les permitía a los sitiados preparar sistemas de defensa activa.

A menudo, el excesivo peso de estos ingenios provocaba que las torres tuvieran dificultades para moverse. Si el terreno sobre el que se desplazaban no se había comprimido bien de forma previa, la arena podía dificultar la circulación. Esta lentitud en su avance permitía que los sitiados pudieran reforzar el sector de la muralla hacia el que se iba a dirigir el ingenio. Los defensores disponían de un tiempo precioso para detener la máquina antes de que alcanzara los muros. De ahí que, la verdadera clave del asedio se encontrara en las maniobras de acercamiento de las torres, pues una vez que habían alcanzado las murallas era muy difícil poder separarlas de ellas.

La altura resultaba fundamental dado el carácter estático de los asedios, ya que de nada servían las torres si se encontraban situadas por debajo de las defensas enemigas. Por tanto, estos ingenios funcionaban como murallas móviles, que se podían acercar o alejar de las murallas de la ciudad, cuyas defensas eran fijas. La movilidad se convertía, así, en una de las principales ventajas que otorgaban estas máquinas a los atacantes frente a los sitiados.

La defensa contra estas torres era complicada y se basaba en intentar igualarlas en altura por todos los medios posibles El combate se establecía entre dos murallas y la más alta siempre tenía mayores posibilidades de éxito Esto llevaba a los sitiados y sitiadores a recrecerlas al máximo, en una carrera frenética para no ser superado.

Una estratagema usada por los sitiadores consistía en hacer las torres de madera más bajas que la muralla para llevar a engaño a los habitantes de la ciudad y que les pillara de sorpresa el levantamiento de la pequeña torre portátil que se encontraba dentro de la torre mayor. También se recurría a la construcción de torres de madera en el interior de las ciudades para aumentar la altura en tramos puntuales, especialmente vulnerables, o que se preveía serían atacados.

La defensa contra las torres de asedio no se limitaba a una cuestión de altura, sino que había que evitar la llegada a los muros, impidiendo que los arietes pudieran abrir brecha. Al mismo tiempo, en la maniobra de acercamiento, las torres contaban con la cobertura que proporcionaban las piezas de artillería dispuestas en sus pisos y que batían las murallas con piedras de grandes dimensiones y dardos de hierro.

Los sitiados también podían hacer trampas ocultas en el suelo con las que obstaculizar a las torres. Éstas consistían en amplios agujeros o trincheras excavadas 
y cubiertas, de forma que pasaran inadvertidas a los atacantes. Al llegar a ese lugar, las torres se hundían o desplomaban, siendo imposible sacarlas y haciendo que cayeran al vacío los soldados que portaban.

Pero, la principal defensa contra estas máquinas era el fuego pues, a priori, era la única forma de destruir totalmente las torres, que estaban fabricadas en madera. Por ese motivo, para protegerlas se recubrían con pieles sin curtir o cuero, aunque la máxima defensa con que se podía dotar una máquina era forrarla totalmente con placas de hierro, lo cual también conseguía amortiguar los impactos de los proyectiles arrojados por las piezas de artillería. Por tanto, si se quería quemar una torre, lo primero que se debía hacer era retirar las pieles que las cubrían o incluso el forro de hierro que, en ocasiones especiales, las protegía.

Cuando el fuego ya había prendido en la estructura, los atacantes tenían que apagarlo antes de que destruyeran estos ingenios tan costosos en su construcción. En las torres de mayores dimensiones también había una especie de galería alrededor. Su principal función era permitir que los soldados pudieran apagar las llamas desde el exterior de la torre, en caso de que éstas prendieran sobre la estructura. Previendo esta eventualidad, cada piso tenía una reserva con depósitos de agua. El vinagre podía ser un buen sustitutivo de este líquido para anular el poderío destructor del fuego, pues contribuía a extinguirlo con mucha facilidad.

La efectividad de estas máquinas dentro del ejército romano, en algunos casos, se basó en el temor que causaban, sobre todo entre los pueblos que nunca habían visto estos ingenios. Este hecho es perfectamente apreciable en la conquista de la Galia por César. Los indígenas quedaron muy asombrados ante el tamaño de las torres y cómo los hombres podían mover semejantes máquinas.

Las legiones romanas llegaron incluso a personificar a las torres de asedio. La principal de ellas empleada en el asedio de Jerusalén era la conocida como Victoria, ya que ninguna ciudad había podido resistir sus ataques. Esta estrategia propagandística era muy propia del ejército y contribuía a fortalecer la moral de las tropas, al mismo tiempo que rodeaba de un aura de invencibilidad a los contingentes legionarios.

\subsection{Superación de las murallas abriendo una brecha a través de ellas}

La principal máquina para abrir brecha en las murallas era el ariete (fig. 3). En cuanto a su diseño, podía adoptar diferentes configuraciones, desde un simple madero hasta pesadas estructuras con ruedas y tejados cubiertos. Sin embargo, básicamente, todos los arietes consistían en un gran tronco de madera, con una cabeza de hierro que se había introducido dentro de una abertura móvil. El frontal metálico solía tener forma de cabeza de carnero, aunque también podía consistir en una serie de dientes afilados que, gracias a su forma de sierra, dañaban con mayor facilidad las piedras. 
Una vez que el ariete estaba próximo a los muros se balanceaba el tronco adelante y hacia atrás en un movimiento de péndulo. Tras ser golpeada la pared y sus piedras movidas se utilizaba la falx muraria, que era una especie de viga con una hoz en uno de sus extremos y que permitía remover los sillares que, previamente, habían sido movidos. Por medio de este sistema se podía abrir una brecha en el muro a través de la cual penetraran los soldados.

Los primeros arietes eran portados y manejados a mano por los soldados hasta la muralla. El uso de estos primeros modelos resultaba muy peligroso, ya que los soldados estaban expuestos a los disparos y a los materiales arrojados por los defensores. De ahí que, tempranamente, esta máquina se dispusiera dentro de otras máquinas de mayores dimensiones y más protegidas, como eran las tortugas o las torres de asedio, en las que ocupaba el primer piso.

Las técnicas de defensa contra los arietes eran muy complejas. Por un lado, se podían coger las cabezas con cuerdas y separarlas de los sillares de la muralla. Gracias a esta estratagema se lograban evitar los golpes directos 0 , al menos, amortiguarlos tanto como fuera posible. Su empleo es muy antiguo y ya está atestiguado en el mundo asirio durante el siglo IX a. C.

Otra estrategia consistía en sujetar por medio de cadenas grandes vigas, de forma paralela al muro. Cuando se acercaba el ariete, los sitiados las dejaban caer para intentar partirlo a la altura de la cabeza y detener su avance. Cualquier material de grandes dimensiones y pesado podía desempeñar esta función de ruptura. Así, las fuentes mencionan el empleo de piedras, troncos o ya bien masas de plomo fundidas que, a causa de su enorme peso, resultaban más contundentes.

También, se podían usar sacos de paja o de cualquier otro material blando, como por ejemplo arena. Por medio de cuerdas era posible dejarlos caer justo delante del lugar donde iba a golpear el ariete, de tal forma que se amortiguaba mucho el impacto de la cabeza. Pero, a pesar de todas estas estratagemas, la defensa más práctica y, a su vez, la más empleada en los asedios consistía en el empleo del fuego. Por medio de sustancias incendiarias podían ser totalmente eliminadas las máquinas de asedio, mientras que con los otros métodos tan sólo se dañaban y era posible volver a reutilizarlas, después de ser reparadas.

El tamaño de esta máquina variaba muchos, desde algunos ejemplares que necesitaban veinte soldados para ser movidos hasta otros de grandes dimensiones con varios cientos o incluso miles de soldados para poder ser puestos en funcionamiento.

Para facilitar las operaciones del ariete se disponía de la máquina conocida como trépano, taladro o terebra. En cuanto a su constitución y estructura, esta máquina era muy semejante a una tortuga. Su única diferencia era que en el centro y, dispuesto a media altura y sujeto por travesaños, se había colocado una especie de canal. Sobre él se desplazaba una viga de madera de grandes dimensiones, con un sistema muy semejante al que desplazaba la corredera de las catapultae. 
Esta viga superior iba armada con una punta de hierro, que era como una especie de barrena, cuya función era agujerear los lienzos de muralla. Para poder cargar la máquina se contaba con un sistema de torno en su parte trasera, lo que facilitaba que la corredera fuera desplazada hacia atrás. Una vez cargado el taladro, se soltaba, lo que provocaba que la viga saliera con fuerza y dañara los muros con su impacto.

\subsection{Las piezas de artillería}

Pero, sin duda alguna, las máquinas más interesantes y que disponían de una mecánica más compleja eran las piezas de artillería.

Las piezas de artillería romanas, al igual que sus antecesoras griegas, se basaban en el principio de torsión de haces de tendones, crines o cabellos humanos, alrededor de bastidores. Hoy en día es muy difícil saber qué clase de tendones y de qué animales eran los más fuertes y elásticos para su empleo, aunque se piensa que, en ningún momento, se utilizarían solos, sino mezclados con pelo animal o humano, de modo que se asegurara su cohesión. La zona de los tendones animales que mejor serviría para estos propósitos sería la correspondiente a los hombros de los bueyes y a los tobillos de los caballos.

Esta falta de información se debe, entre otras cosas, a que los tendones, al tratarse de un material orgánico, no se han conservado en el registro arqueológico. Por si esto fuera poco, ninguno de los tratados que han llegado hasta nosotros describe la preparación de los tendones de animales para las piezas de artillería de torsión.

Las piezas de artillería podían ser de dos brazos o de uno sólo, aunque todas tenían la misma mecánica:

El núcleo de las catapultas de torsión de dos brazos era un bastidor de made$\mathrm{ra}$, de forma rectangular con dos largueros y cuatro postes. Junto a cada extremidad de los largueros se ubicaba un orificio (foramen), tanto en la parte inferior como en la superior, que servía para alojar los dos muelles de cuerda. En cada uno de esos orificios se situaba un modiolus (cojinete cilíndrico y hueco construido en bronce) con un epizygis (pequeña barrita de hierro), que lo atravesaba diagonalmente y que se encajaba en las muescas de su parte superior.

Las máquinas de torsión podían dividirse en euthytonas y palintonas. En las máquinas euthytonas, el ángulo recorrido por los brazos era muy pequeño $\left(23^{\circ}\right.$ en las primeras y más tarde $35^{\circ}$ ) y por tanto eran aptas para arrojar flechas que pesaban muy poco. A causa de la escasa potencia no podían arrojar piedras, que pesaban demasiado. El lanzamiento de proyectiles pétreos exigía que el ángulo recorrido por los brazos fuera mucho mayor para que resultaran efectivas. La necesidad de alcanzar los $45050^{\circ}$ dio lugar a las máquinas palintonas. 
En cuanto al resto de elementos de las piezas de artillería, entre los dos postes del bastidor y, de forma perpendicular, se situaba la caña, que era una barra de madera con una ranura longitudinal de sección en cola de milano en su cara superior. Encajada en esa ranura había otra barra móvil conocida como corredera que, justo en su parte superior, poseía una ranura para guiar la dirección de la flecha. En la parte posterior estaba el sistema de gatillo y el torno. El gatillo tenía un dispositivo de balancín con una garra de pestillo bífido. En cuanto al torno, constaba de una rueda dentada, que era descorrida con la ayuda de palos.

Para poder armar las catapultas, se llevaba la corredera hacia delante, de modo que la garra pudiera atrapar la cuerda, inmovilizando el gatillo. Después, se volvía la corredera hasta la posición retraída con la ayuda del torno y se lograban tensar los brazos. Al soltar el gatillo, la cuerda se liberaba e impulsaba la flecha por el canal de la corredera. Cuando se trataba de catapultas de pequeño calibre se armaban a mano con barras dentadas en el lateral de la caña, que sujetaban la corredera retraída. Sin embargo, en las máquinas de mayores dimensiones era necesario el uso de algún sistema de poleas.

La importancia de las maquinas de torsión residía en que su fuerza era mucho mayor, además de su capacidad de precisión, ya que se basaban en un sistema de fuego más directo y menos parabólico. Al disparar de forma directa era mucho más fácil apuntar, pues la línea descrita por el proyectil era recta en su camino hacia el blanco.

La principal pieza de artillería para lanzar flechas durante la República y el Imperio era la catapulta tipo scorpio (fig. 4). El nombre de scorpio se refiere a lo letal de sus proyectiles como arma antipersonal. Esta pieza de artillería suponía la artillería básica de campaña a causa de su reducido tamaño y peso, que se situaba en torno a los 50 o 60 kilos. El uso generalizado de esta máquina se debía a que, gracias a su peculiar diseño, hacía que fuera posible desmontarla en tres piezas bien diferenciadas: capitulum, caña y corredera, y base. Esta peculiaridad facilitaba su transporte y empleo en batallas campales.

Las flechas que arrojaba eran de pequeño tamaño, de aproximadamente unos $70 \mathrm{~cm}$., de ahí el nombre de tres palmos que le dieron los griegos a esta misma arma. La precisión de esta máquina era tal que podía acertar a una distancia de 500 metros sobre blancos individuales. De ahí que se le apodara escorpión, por sus efectos letales semejantes a la mordedura de este animal.

La ballista era la principal máquina para arrojar piedras de dos brazos, empleada hasta que fue desbancada con la puesta en marcha del onager, de un solo brazo, ya durante el siglo II d. C. Su tamaño variaba enormemente y las fuentes hablan de máquinas gigantescas, aunque esto puede ser fruto de la reflexión teórica de los autores o de la mera propaganda de los cronistas del ejército. Sin embargo, con total seguridad, existían máquinas de más de 8 metros de altura, a tenor de los proyectiles hallados. 
Sin embargo, el modelo estándar de máquina para lanzar piedras en el ejército romano imperial fue el onager, que era una máquina con tecnología de torsión, pero de un solo brazo.

Los cinco principales componentes del onager eran:

- Una base sólida de madera.

- Un brazo con una honda en el extremo para lanzar.

- Un resorte de torsión horizontal.

- Una cuerda y un mecanismo de torno para bajar el brazo hacia abajo

- Una barra transversal pesada con relleno para detener el movimiento del brazo cuando fuera lanzado.

El onager no era tan exacto como lo podían ser las máquinas bélicas del tipo ballista, ya que no poseía una base separada ni tampoco una junta universal que facilitara los movimientos. El principal inconveniente de su empleo era que los proyectiles describían un ángulo más alto de tiro y, por tanto, era muy difícil precisar a la hora de disparar.

Es muy difícil saber cuál sería el tamaño y el peso de esta máquina, aunque debía ser significativamente mayor que las maquinas para lanzar piedras de dos brazos. Su peso, en función del tipo de máquina, se encontraría entre las 2 y las 6 toneladas. A causa de su elevado peso resultaba muy difícil corregir las trayectorias para apuntar a nuevos blancos, lo que la convertía en una máquina bastante estática.

Acompañado de este descomunal peso, también poseía un enorme retroceso, lo que provocaba que la máquina tuviera que ser colocada sobre plataformas de lanzamiento con montones de césped o de ladrillos que amortiguaran los golpes, ya que si se colocaba sobre estructuras de piedra se corría el riesgo de que las destruyera.

Mientras que en una ballista de dos brazos dos artilleros eran capaces de apuntar a un objetivo, el equipo necesario para poner en marcha esta máquina requeriría de un número mayor. El número de artilleros para hacerla funcionar sería de cinco a seis hombres, aunque Vegecio sugiere que al menos harían falta once y Amiano apunta la presencia de ocho para dotar de efectividad esta máquina. Harían falta cuatro para poner el brazo desde una posición vertical hasta una horizontal, un artillero y un comandante para dar las órdenes, además de los que transportaban la munición. Esta máquina, debido a la simpleza de su mecanismo, era la máquina pesada más fácil de manejar. Era la menos maniobrable de las catapultas, pero también la que tenía un efecto mucho más devastador.

La quiroballista supuso el último de los pasos evolutivos de la artillería de torsión, en su forma para lanzar flechas. Los armazones de madera de los resortes 
pasaron a convertirse en unos cilindros de bronce, que sustituían a las mordazas. Eran más resistentes que los anteriores y protegían las madejas de la lluvia y de otras causas de deterioro.

Las catapultas de época tardo-republicana eran demasiado pesadas y embarazosas para ser desplazadas por el frente de batalla. De ahí que, el armazón de madera de las máquinas lanzaflechas de torsión fuera sustituido por un marco metálico, que aligeraba el conjunto y reducía la máquina a su mínima expresión. Se lograba un ahorro de peso clave, de cara a la movilidad necesaria en las batallas en campo abierto.

El nuevo sistema empleado en la fabricación de la quiroballista permitía reemplazar dentro del combate el módulo estropeado por otro de reserva. Además, introducía la novedad de que permitía transportar las piezas de artillería montadas hasta el lugar del combate, lo que dio lugar a una nueva máquina: la carroballista. Hasta su aparición, las máquinas, por partes, eran desplazadas en bestias de carga o vía marítima. Eso hacía que llegaran tarde a los enfrentamientos y que se requiriera mucho tiempo para conseguir que estuvieran operativas. Las batallas campales, a menudo, no eran preparadas con anterioridad por lo que, si no se llevaban las máquinas con el ejército, no se podía esperar a que llegaran. La carroballista había supuesto la última innovación de la artillería de torsión romana.

\section{CONCLUSIÓN}

A pesar de todo el despliegue de medios que suponían las máquinas de asedio, la verdadera clave del enfrentamiento se encontraba en la moral. Una pérdida de moral entre los sitiados podía empujarles a la rendición. Y, la presencia de un jefe respetado al frente de sus tropas era capaz de incitarlas a la realización de grandes obras. Algo que también podía afectar de forma definitiva al desenlace de un enfrentamiento era la caída del general en el campo de batalla. De un modo o de otro, cualquier bajada de moral en uno de los dos bandos terminaba por decantar el conflicto.

Tras la toma de las ciudades solía quedar muy poco espacio para la clemencia. Con frecuencia, los habitantes, en el caso de que hubieran resistido durante mucho tiempo el asedio, eran masacrados y ni siquiera se respetaba a las mujeres, niños o ancianos. Y los que no morían en estos episodios de barbarie terminaban sus días como esclavos.

Incluso en el caso de que el jefe atacante se inclinara por concederles la libertad a los defensores capturados, se corría el riesgo de que los soldados perdieran la cabeza por su codicia y llevaran a cabo atropellos contra la población civil. Este era el motivo por el que, tras la conquista de una ciudad, los generales dieran, en ocasiones, órdenes para apostar guardias en las puertas e impedir que la tropa irrumpiese en el interior del recinto amurallado. 
Pero, en ocasiones, la indulgencia llegaba incluso a los soldados que formaban la guarnición, pues se tenía en cuenta que se limitaban a cumplir las órdenes de sus superiores. Los prisioneros podían recibir un buen trato, siempre que el atacante no faltara a su palabra de honor, algo que solía suceder con demasiada frecuencia.

Como conclusión, se puede afirmar que con el desarrollo de las ciudades también surgió la poliorcética como ciencia. La ayuda de las máquinas permitió doblegar un gran número de ciudades desde la Península Ibérica hasta Iraq. Sin el apoyo que supusieron los nuevos descubrimientos, por ejemplo, la ciudad de Jerusalén, nunca hubiera caído en manos romanas. $\mathrm{Y}$, a pesar del empleo de la maquinaria a gran escala, las murallas resistieron durante mucho tiempo las embestidas del ejército romano.

La puesta en funcionamiento de las máquinas de asedio influyó de forma notable en las consideraciones bélicas del ejército romano. Su aplicación le permitió a las legiones ampliar las concepciones de conquista y ocupación para territorios extensos. Con su ayuda, los ejércitos podían alcanzar los fines propuestos en un tiempo menor y con menos costes.

\section{BIBLIOGRAFÍA}

Adcock, F. E. (1940): The Roman Art of War under the Republic, Cambridge, Mass.

AleXANDER, L. (1946): «Greek and Roman Artillery», C.J., 41.

BORGATTI, M. (1927): La tecnica nell' esercito romano, Roma.

Brisson, J. P. (1969): Problemes de la guerre à Rome, París - La Haya.

CAmpbelL, D. B. (1997): «The Roman Art of War», Britannia, 28.

Campbell, J. B. (1994): The Roman Army, 31 BC - AD 337: a sourcebook, Routledge, London.

CampbeL, D. B. (2003a): Greek and Roman Artillery 399 BC - AD 363, Osprey New Vanguard, 89, London.

Campbet, D. B. (2003b): Greek and Roman Siege Machinery 399 BC - AD 363, Osprey New Vanguard, 78, London.

Clausetti, E. (1942), «L'ingenieria militare dei Romani», Quaderni dell’ Impero, XVIII, Roma, 1-25.

ClauseWitZ, K. V. (1980), De la Guerra, Madrid.

Connolly, P. (1989), Las legiones romanas, Anaya, Madrid.

- (1998), Greece and Rome at war, Oxford - Londres.

Cordente, F. (1991), Poliorcética romana: 218 a. C. - 73 d. C., Tesis doctoral inédita leída en la Universidad Complutense de Madrid, 1991.

DeLBRÜCK, H. (1990), Warfare in antiquity, University de Nebraska, Lincoln.

Drachmann, A. G. (1963), The Mechanical Technology of Greek and Roman Antiquity, Copenhague.

ELTON, H. (1996), Warfare in Roman Europe AD 350 - 425, Oxford.

Foley, V., PALmer, G. y Soedel, W. (1985): «La Ballesta», Investigación y Ciencia, 102, 76-83.

FRAU, B. (1987): Tecnología greca e romana, Roma.

GaBBA, E. (1982): Tecnología militare antica, In Tecnología, economía e società nel mondo romano, Tai del Convengo de Cómo, Cómo, 219 - 234.

GARLAN, Y. (1974): Recherches de poliorcetique grecque, París.

Goldsworthy, A. K. (1996): The Roman Army at War 100 BC - AD 200, Clarendon Press, Oxford.

Hodges, H. (1968): Artifacts, Londres.

- (1970), Technology in the Ancient world, Londres.

Hoffmeyer, A. B. (1958): Antikens Artillery, Bonn.

HoldeR, P. (1987): Roman Artillery I, Military Illustrated, 2.

Humble, R. (1980): Warfare in the Ancient World, Cassell, London. 
Humphrey, J.; Oleson, J. P. y Sherwood, A. N. (1998): Greek and Roman Technology: a Sourcebook, Londres.

LAFAYE, G. (1919): Tormentum, Dictionnaire des antiquités grecques et romaines V, París, 1919, pp. 363372.

LANDELS, J. G. (1978): Engineering in the Ancient World, London.

LiberAtI, A. M. y Silverio, F. (1990): La legioni di Roma, Fratelli Palombi Editori, Roma.

MARSDEN, E. W. (1999a): Greek and Roman Artillery. Historical Development, Oxford University Press, 2. ${ }^{a}$ Edición, London.

MARSDEN, E. W. (1999b): Greek and Roman Artillery. Technical Treatises, Oxford University Press, 2. ${ }^{a}$ Edición, London.

MinozzI, L. (1936): Artiglerie e costruzioni di guerra degli antichi.

Peddie, J., Alan B. y Lloyd, A. (1994): The Roman War Machine, Gerald Duckworth \& Co. Ltd., London.

PEDdIE, J. (1997): The Roman War Machine, Stroud.

RICHMOND, I. A. (1945): Roman Artillery, Oxford.

- (1970): Roman military engineering, Roman Archaeology an Art, London.

SÁEZ ABAD, R. (2005): La poliorcética en el Mundo Antiguo, tesis doctoral leída en la Universidad Complutense el 25 de junio de 2004, Universidad Complutense Servicio de Publicaciones.

Schramm, E. (1918), Die antiken Geschütze der Saalburg.

- (1928): Poliorketik, In Kromayer - Veith, Munich.

SHIPP, G. P. (1960), «Ballista», Glotta, 39.

Soedel, W. y Folley, V. (1979), «Catapultas antiguas», Investigación y Ciencia, 32, Madrid, 92-101.

Sprague de Camp, L. (1983): The Ancient Engineers, Ballantine Books, USA. 